MATEC Web of Conferences 25,02005

(2015)

DOI: $10.1051 /$ matecconf/ 20152502005

(C) Owned by the authors, published by EDP Sciences, 2015

\title{
Research of Characteristics of Gas-liquid Two-phase Pressure Drop in Microreactor
}

Dan Li

Chemical Institute of Chemical Industry, Xi'an Shiyou University, Xi'an, Shaanxi, China

\begin{abstract}
With the research system of nitrogen and deionized water, this paper researches the pressure drop of gas-liquid two-phase flow in the circular microchannel with an inner diameter which is respectively $0.9 \mathrm{~mm}$ and $0.5 \mathrm{~mm}$, analyzes the effect of microchannel diameter on gas-liquid two-phase frictional pressure drop in the microchannel reactor, and compares with the result of frictional pressure drop and the predicting result of divided-phase flow pattern. The result shows that, the gas-liquid two-phase frictional pressure drop in the microchannel significantly increases with the decreasing microchannel diameter; Lockhart-Martinelli relationship in divided-phase flow pattern can preferably predict the gas-liquid two-phase frictional pressure drop in the microchannel, but the Tabular constant needs to be corrected.
\end{abstract}

Keywords: microreactor; gas-liquid two-phase flow; pressure drop

\section{INTRODUCTION}

Compared with the reactor under a macro scale, the characteristics of fluid manifested in the microchannel reactor are very different from it, because the decrease of characteristic scale of the channel will result in the increase of surface tension and enhancement of wall restrictions. The research of gas-liquid two-phase flow pressure drop must be done under a certain specific flow pattern, because the characteristic of gas-liquid two-phase flow pressure drop is different in different flow patterns ${ }^{[1-3]}$. The divided-phase flow pattern adopted by gas-liquid two-phase pressure drop in the conventional pipeline assumes that each phase of flow is continuous in two phases, and considers the interaction between two phases. The interaction of gas-liquid interface in the process of gas-liquid two-phase flow in the microchannel is enhanced ${ }^{[4,5]}$, so the divided-phase flow pattern is applicable within a certain scope. That is, the gas phase flow can break a continuous phase which is formed by the liquid phase. Many researchers have corrected the divided-phase flow patterns, and fitted well with their experimental results. However, a proposal of a large number of corrected patterns is lack of consensus, so it is easy to cause confusion on the awareness of the problem, and there is a need of more researches and experimental data to establish a unified opinion. The researches examine the characteristics of pressure drop in the process of gas-liquid two-phase flow in the circular microchannel with an inner diameter which is respectively $900 \mu \mathrm{m}$ and $500 \mu \mathrm{m}$, and analyze the effect of microchannel diameter on gas-liquid two-phase flow pressure drop, and compare the result with the predicting result of divided-phase flow pattern.

\section{EXPERIMENTAL FACILITIES}

The schematic diagram of experimental facilities is shown in Figure 1. The experiment adopts the microchannel reactors, which are two kinds of circular microchannels with the diameter which is respectively $500 \mu \mathrm{m}$ and $900 \mu \mathrm{m}$, and the texture of quartz. The facility is comprised of a microchannel reactor, Y-shaped joint and gas-liquid phase flow control system. The diameter of connecting channel in three directions inside the Y-shaped joint is the same with the inner diameter of the connected circular microchannel and the angle is $120^{\circ}$. In the process of experiment, $\mathrm{N}_{2}$ passes the reducing valve, and its flow is precisely controlled by a mass flow controller; a set of pressure sensor can be connected with the gas inlet pipe of Y-shaped microchannel reactor to measure pressure in this place. Liquid is at a constant temperature environment, and liquid flow is regulated and controlled by a set of precision constant-flux pump. Liquid flows through the constant-flux pump and into a buffer tank. The gas-liquid two-phase cross flows into the microchannel reactor for mixing, and then into horizontally placed quartz tube.

\section{RESULTS AND DISCUSSION}

\subsection{Effects of microchannel diameters on frictional pressure drop}

Figure 2 shows the change trend of frictional pressure drop under two sets of superficial liquid velocity (The $U_{L}=0.129 \mathrm{~m} / \mathrm{s}$ and $U_{L}=0.126 \mathrm{~m} / \mathrm{s}$ is a set, and the $U_{L}=1.650 \mathrm{~m} / \mathrm{s}$ and $U_{L}=1.666 \mathrm{~m} / \mathrm{s}$ is the other set) when the diameter is respectively $500 \mu \mathrm{m}$ and 900 $\mu \mathrm{m}$. 


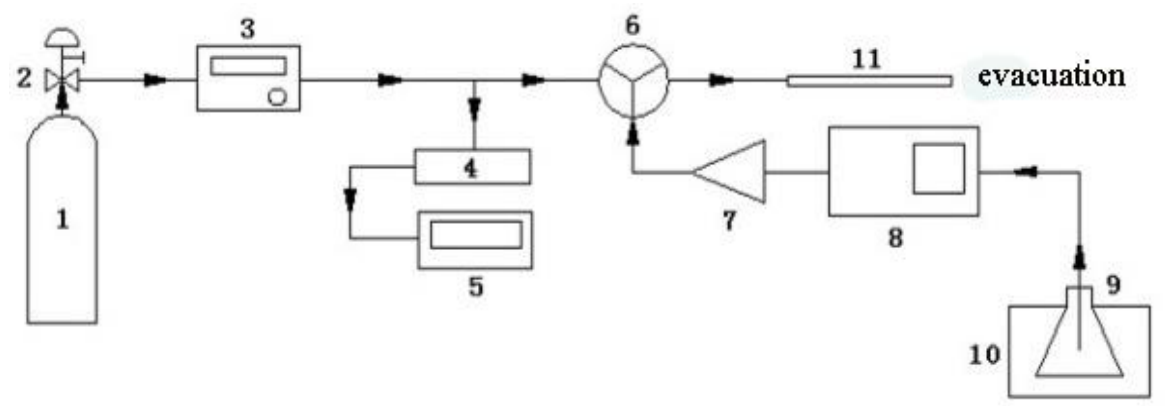

1- $\mathrm{N}_{2}$ steel cylinder; 2-Reducing valve; 3-Gas flow control meter; 4-Pressure sensor; 5-Pressure indicator; 6-Y-shaped joint; 7-Buffer 8-Pump; 9-Conical flask; 10-Constant temperature water area; 11-Drainage pipe.

Figure 1. Schematic representation of the experimental setup

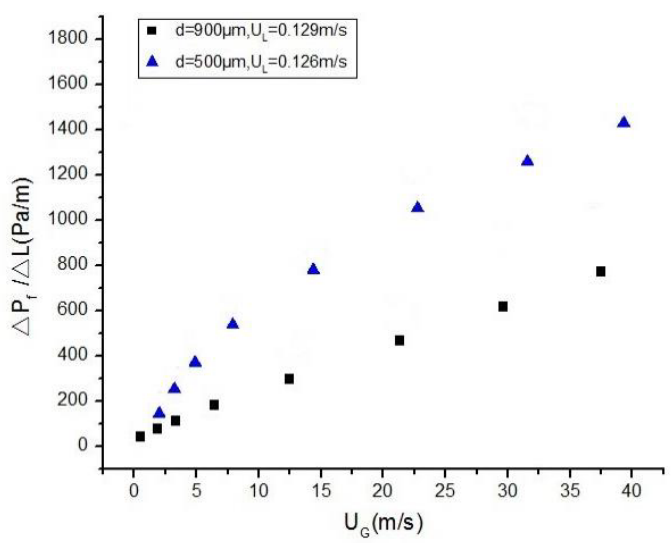

(a)

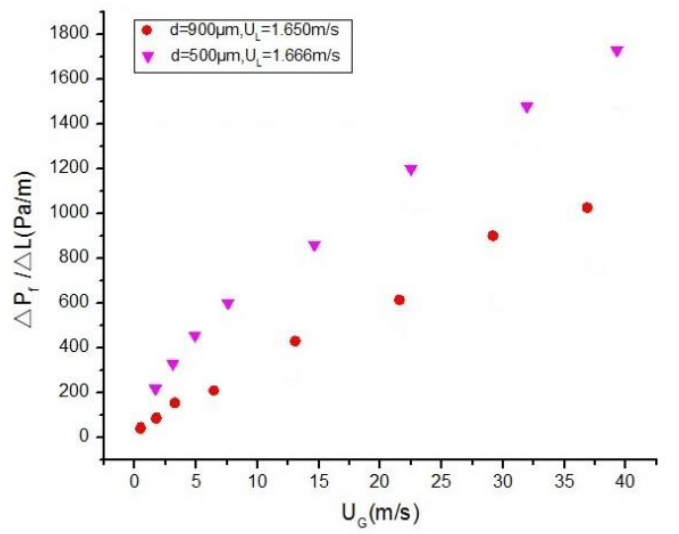

(b)

Figure 2. Effects of microchannel diameters on frictional pressure drop

As can be seen from Figure 2, to reduce the microchannel diameter under the same superficial velocity, the gas-liquid two-phase frictional pressure drop is significantly increased because with the decrease of microchannel diameter, the function of surface tension is significantly enhanced; the microchannel wall is more difficult to be moistened by liquid; the viscous resistance of microchannel wall for fluid becomes large, finally resulting in the increase of gas-liquid two-phase frictional pressure drop in the microchannel.

\subsection{Divided-phase flow pattern}

The divided-phase flow pattern is a more commonly-used pattern for researchers to investigate the gas-liquid two-phase flow pressure drop in small channels or microchannels. The divided-phase flow pattern considers the interaction between gas-liquid phase flows. The researchers believe that the interaction between gas-liquid phase flows may not be ignored in microchannels ${ }^{[6,7]}$. Common pattern is proposed by Lockhart ${ }^{[8]}$ and others, it is expressed as follows:

$$
\left(\frac{\Delta P_{\mathrm{f}}}{\Delta L}\right)_{\mathrm{tp}}=\Phi_{\mathrm{L}}^{2}\left(\frac{\Delta P_{\mathrm{f}}}{\Delta L}\right)_{\mathrm{L}}
$$

Where the Lockhart-Martinelli is proposed, it is defined as:

$$
X^{2}=\frac{\left(\Delta P_{\mathrm{f}} / \Delta L\right)_{\mathrm{L}}}{\left(\Delta P_{\mathrm{f}} / \Delta L\right)_{\mathrm{G}}}
$$

Where $\left(\Delta P_{\mathrm{f}} / \Delta L\right)_{\mathrm{L}}$ and $\left(\Delta P_{\mathrm{f}} / \Delta L\right)_{\mathrm{G}}$ respectively represent the gradient of frictional pressure drop when liquid and gas separately flow in the channel. Chisholm ${ }^{[9]}$ later proposes a more precise formula to describe this relationship:

$$
\Phi_{\mathrm{L}}^{2}=1+\frac{C}{X}+\frac{1}{X^{2}}
$$


Constant $\mathrm{C}$ is Tabular constant, and its value is related to two-phase flow conditions in the channel. The value of coefficient $\mathrm{C}$ is shown in Table 1 :

\begin{tabular}{lll} 
Table 1. Values of C & \\
\hline $\begin{array}{l}\text { Gas phase } \\
\text { Flow condition }\end{array}$ & $\begin{array}{l}\text { Liquid phase } \\
\text { Flow condition }\end{array}$ & Values of C \\
\hline Laminar flow & Laminar flow & 5 \\
Laminar flow & Turbulent flow & 10 \\
Turbulent flow & Laminar flow & 12 \\
Turbulent flow & Turbulent flow & 20 \\
\hline
\end{tabular}
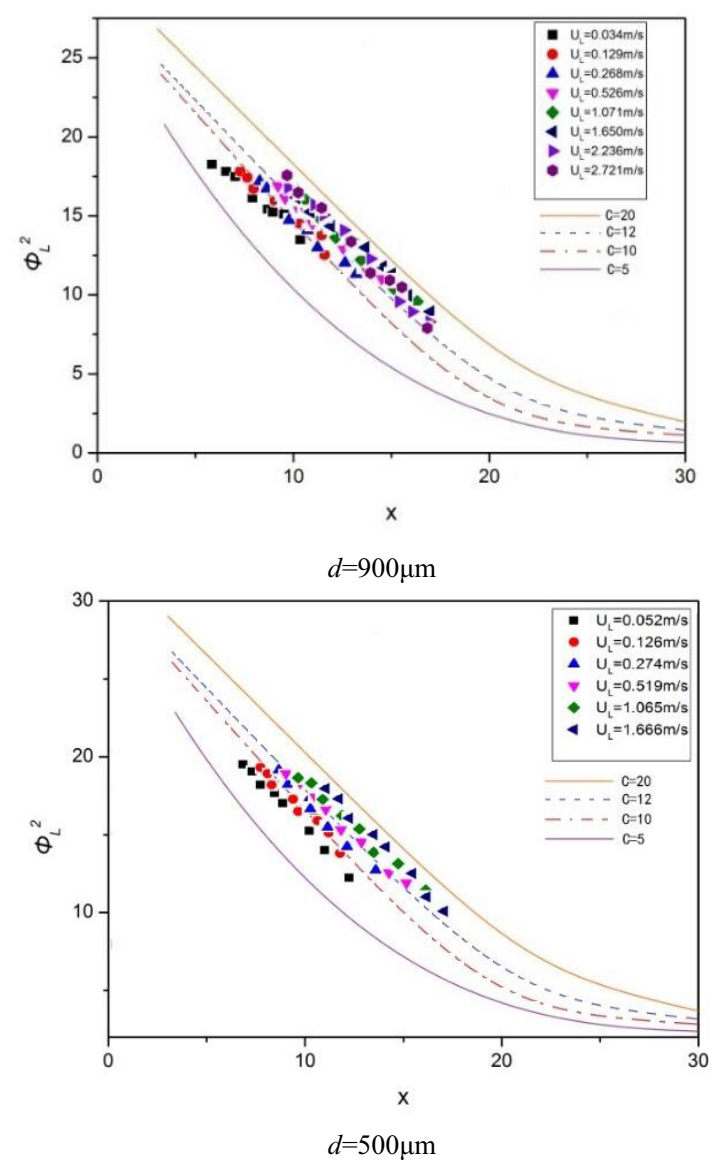

Figure 3. Two-phase frictional multiplier as a function of Lockhart-Martinelli factor in microchannels

Under the experimental operating conditions, the apparent Reynolds number of gas and liquid phases is less than 2000, so the condition of gas-liquid two-phase flow in microchannels is laminar flow. Figure 4 shows a related graph of $\Phi_{\mathrm{L}}^{2}$ value measured through experiment and $X$ in the microchannel with the diameter which is respectively $900 \mu \mathrm{m}$ and $500 \mu \mathrm{m}$.
According to Table 1, the value of constant $\mathrm{C}$ in Chisholm equation is 5. However, as shown in Figure 4 , prediction curve in Chisholm equation shows that the value of $\mathrm{C}$ corresponding to data which is obtained from experiment varies from 5 to 20 , indicating that the predicted value of Lockhart-Martinelli relationship is lower than the experimental results. Therefore, the direct use of Lockhart-Martinelli relationship to predict the data of two-phase frictional pressure drop may lead to a larger deviation. In addition, the figure shows that, with the increase of superficial velocity, the constant $\mathrm{C}$ gradually increases, because the gas-liquid two-phase flow transits from laminar flow to turbulent flow with the increase of superficial velocity, indicating that the value of constant $\mathrm{C}$ is related to the size of gas-liquid superficial velocity. Dai L. ${ }^{[10]}$ has amended the constant $\mathrm{C}$, it is shown as follows:

When $d_{i}=0.5 m m, C=2.295 \operatorname{Re}_{L}^{0.258} \operatorname{Re}_{G}^{0.0117}$

When $d_{i}=0.3 m m, C=2.312 \operatorname{Re}_{L}^{0.121} \operatorname{Re}_{G}^{0.19}$

According to formulas (1)-(3), the relationship between the pressure drop and the constant $\mathrm{C}$ is as follows:

$\frac{\Delta P_{f}}{\Delta L}=\left(\frac{\Delta P_{f}}{\Delta L}\right)_{L}+C \sqrt{\left(\frac{\Delta P_{f}}{\Delta L}\right)_{L}\left(\frac{\Delta P_{f}}{\Delta L}\right)_{G}}+\left(\frac{\Delta P_{f}}{\Delta L}\right)_{G}$

Then we can obtain:

$C=\left[\left(\frac{\Delta P_{f}}{\Delta L}\right)-\left(\frac{\Delta P_{f}}{\Delta L}\right)_{L}-\left(\frac{\Delta P_{f}}{\Delta L}\right)_{G}\right] / \sqrt{\left(\frac{\Delta P_{f}}{\Delta L}\right)_{L}\left(\frac{\Delta P_{f}}{\Delta L}\right)_{G}}$

Figure 5 is a schematic diagram of the effect of microchannel diameter on Tabular constant C. As shown in this figure, with the increase of microchannel diameter, Tabular constant $\mathrm{C}$ significantly becomes larger, and some other researchers ${ }^{[11,12]}$ point out the following rules. Without explicit report, such rules have been recognized by most researchers. Taking the Lee and others' relationship of Tanular constant $\mathrm{C}$ as an example, it is expressed as follows:

Laminar flow: $C=2.16 \operatorname{Re}_{L}{ }^{0.047} W e_{L}^{0.60}$

Turbulent flow: $C=1.45 \operatorname{Re}_{L}{ }^{0.25} W e_{L}{ }^{0.23}$

Transform above two formulas into:

$$
\begin{aligned}
& C=2.16\left(\frac{U_{L S} \rho_{L} d}{\mu_{L}}\right)^{0.047}\left(\frac{U_{L S}{ }^{2} \rho_{L} d}{\sigma}\right)^{0.60} \\
& =2.16 \frac{U_{L S}{ }^{1.247} \rho_{L}^{0.647} d^{0.647}}{\mu_{L}^{0.047} \sigma^{0.60}} \\
& C=1.45\left(\frac{U_{L S} \rho_{L} d}{\mu_{L}}\right)^{0.25}\left(\frac{U_{L S}{ }^{2} \rho_{L} d}{\sigma}\right)^{0.23} \\
& =1.45 \frac{U_{L S}{ }^{0.71} \rho_{L}^{0.48} d^{0.48}}{\mu_{L}^{0.25} \sigma^{0.23}}
\end{aligned}
$$




\section{MATEC Web of Conferences}

From equations (13) and (14), if other conditions remain unchanged, the value of constant $\mathrm{C}$ will increase with the increase of microchannel diameter.

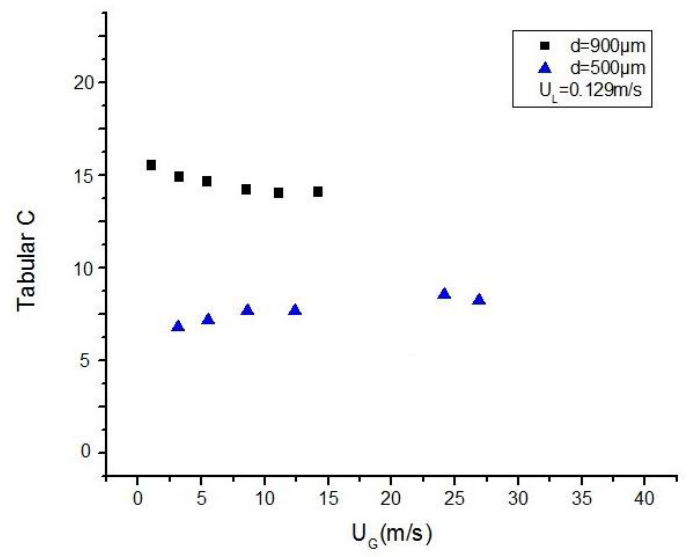

(a)

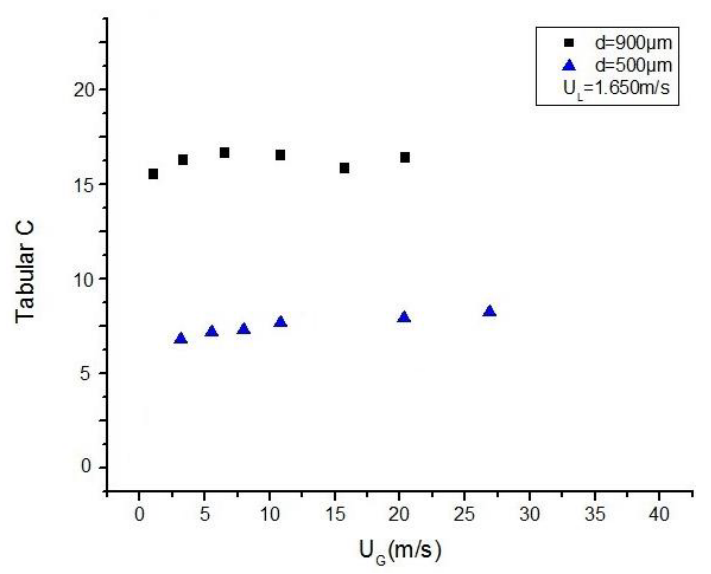

(b)

Figure 4. Tabualr $\mathrm{C}$ as a function of gas superficial velocity in circular horizontal microchannels with different diameters

\section{RESULTS AND DISCUSSION}

1) Within the scope of Reynolds number $(<2000)$ researched in the experiment, the frictional pressure drop of $\mathrm{N}_{2}$ and water in the microchannel reactor with the diameter which is respectively $0.9 \mathrm{~mm}$ and $0.5 \mathrm{~mm}$ will increase with the decrease of microchannel diameter. Therefore, the characteristic of fluid laminar flow in the microchannel reactor with an equivalent diameter of several hundred microns is still in line with the traditional theory.

2) The Lockhart-Martinelli relationship in the divid- ed-phase flow pattern can predict the gas-liquid two-phase flow frictional pressure drop, but the Tabular constant $\mathrm{C}$ requires further amendment. In the experiment, with the increase of gas-liquid superficial velocity, the constant $\mathrm{C}$ gradually increases and it is related to the microchannel diameter. However, the amendment of constant $\mathrm{C}$ still requires more experimental data.

\section{REFERENCES}

[1] Cheng L.X, Ribatski G. \& Thome J.R. 2008.Two-phase flow patterns and flow-pattern maps: Fundamentals and applications. Applied Mechanics Reviews, 61(5): 28.

[2] Rebrov E.V. 2010. Two-phase flow regimes inmicrochannels. Theoretical Foundations of Chemical Engineering, 44(4): 355-367.

[3] Tsoligkas A.N, Simmons M.J.H. \& Wood J. 2006. Two phase gas-liquid reaction studies in a circular capillary Chemical Engineering Science, 62(18-20): 5397-5401.

[4] Choi, C.W., Yu, D.I. \& Kim, M.H. 2011. Adiabatic two-phase flow in rectangular microchannels with different aspect ratios: Part I - Flow pattern, pressure drop and void fraction. International Journal of Heat and Mass Transfer, 18(54): 616-624.

[5] English, N.J. \& Kandlikar, S.G. 2006. An experimental investigation into the effect of surfactants on air-water two-phase flow in minichannels. Heat Transfer Engineering, 88(27): 99-109.

[6] Choi, C.W., Yu, D.I. \& Kim, M.H. 2011. Adiabatic two-phase flow in rectangular microchannels with different aspect ratios: Part I - Flow pattern, pressure drop and void fraction. International Journal of Heat and Mass Transfer, 76(54): 616-624.

[7] English, N.J. \& Kandlikar, S.G. 2006. An experimental investigation into the effect of surfactants on air-water two-phase flow in minichannels. Heat Transfer Engineering, 57(27): 99-109.

[8] Lockhart, R.W \& Martinelli, R.C.1949. Proposed correlation of data for isothermal two-phase, two-component flow in pipes. Chemical Engineering Progress, (45): 39-48.

[9] Chisholm, D. 1967. A theoretical basis for the Lockhart-Martinelli correlation for two-phase flow. International Journal of Heat and Mass Transfer, (10): 1767-1778.

[10]Dai L. 2010. Study of Flow Pattern and Pressure Drop of Gas-liquid Two Phase Flow in Microchannel. Tianjin: Tianjin University

[11]Mishima, K. \& Hibiki, T. 1996. Some characteristics of air-water two-phase flow in small diameter vertical tubes. International Journal of Multiphase Flow, (22): 703-712.

[12]Lee, H.J. \& Lee, S.Y. 2001. Pressure drop correlations for two-phase flow within horizontal rectangular channels with small heights. International Journal of Multiphase Flow, (27): 783-796. 